\title{
Promosi Kesehatan Sebagai Usaha Menurunkan Tekanan Darah Penderita Hipertensi
}

\author{
Annaas Budi Setyawan ${ }^{1}$, Ramdhany Ismahmudi ${ }^{2}$ \\ ${ }^{1,2}$ Universitas Muhammadiyah Kalimantan TImur \\ ${ }^{3}$ Program Studi D-III Keperawatan Fakultas Ilmu Kesehatan \\ e-mail:*1abs564@umkt.ac.id
}

\begin{abstract}
Abstrak
Lokasi pengabdian masyarrakat dilaksanakan di Jalan Pangeran Antasari Gg. Mansyur RT.3 Kelurahan Teluk Lerong Ulu Kota Samarinda. Survey saat kunjungan didapatkan bahwa warga memiliki kebiasaan mengkonsumsi makanan olahan asin seperti jukut pija yang merupakan olahan ikan asin asli dari suku Kutai, sehingga berdampak pada meningkatnya tekanan darah. Metode pengabdian masyarakat yang digunakan yaitu pendidikan kesehatan tentang bahaya dan pencegahan hipertensi, memberikan simulasi pembuatan teh bawang dayak untuk menurunkan tekanan darah, pelatihan pengisian lembar observasi bagi anggota keluarga penderita hipertensi. Hasil pengabdian masyarakat dilihat dari penurunan rata-rata sistol dan diastole tekanan darah penderita hipertensi. Hal ini menunjukkan kegiatan promosi kesehatan merupakan salah satu upaya membantu masyarakat dalam menurunkan angka kejadian hipertensi di komunitas dengan meningkatkan pengetahuan sehingga terjadi perubahan perilaku dan sikap dalam menjalankan perilaku hibup sehat dengan mengkonsumsi makanan rendah garam sehingga tekanan darah bisa turun mendekati normal. Diharapkan program promosi kesehatan tentang hipertensi dapat terus dilaksanakan oleh petugas pelayanan kesehatan komunitas khususnya oleh Puskesmas.
\end{abstract}

Kata kunci-Hipertensi, Tekanan Darah, Promosi Kesehatan

\section{PENDAHULUAN}

Kesehatan merupakan hal penting bagi kualitas hidup manusia, dimana kesehatan merupakan keadaan sejahtera dari badan, jiwa dan sosial yang memungkinkan setiap orang hidup produktif secara sosial dan ekonomis. Dengan demikian pemeliharaan kesehatan diperlukan dalam upaya penanggulangan dan pencegahan yang memerlukan pemeriksaan, pengobatan dan perawatan untuk memulihkan status kesehatan (Parmawati, 2012).

Status kesehatan seseoang dapat dipengaruhi oleh faktor biologik, faktor perilaku, faktor lingkungan dan fakor pelayanan kesehata. Faktor biologik merupakan faktor yang berasal dari individu yang bersangkutan yang disebut juga faktor keturunan. Jika kedua faktor tersebut baik maka seseorang masuk dalam keadaan sehat. Keadaan sehat merupakan kehandak semua pihak. Tidak hanya oleh perorangan tetapi juga oleh kelompok dan bahkan oleh masyarakat, oleh sebab itu sejalan dengan upaya bidang kesehatan dan kemajuan tekhnologi di bidang kesehatan maka status kesehatan harus terus ditingkatkan terutama pada masalah-masalah yang dapat mengahambat pola aktivitas dan produktivitas, salah satunya hipertensi (Garnadi, 2012).

Hipertensi yang tidak segera ditangani berdampak pada munculnya penyakit degeneratif, seperti penyakit jantung, gagal ginjal dan penyakit pembuluh darah perifer. Dari seluruh penderita hipertensi 90-95 melaporkan hipertensi esensial atau hipertensi premier 
yang penyebabnya tidak diketahui. Hal ini jika tidak dilakukan penanggulangan dengan baik keadaan ini cenderung akan meningkat (Sutaryo, 2011).

Lokasi pengabdian masyarakat tepatnya dilaksanakan di Jalan Pangeran Antasari Gg. Mansyur RT.3 Kelurahan Teluk Lerong Ulu Kota Samarinda. Lokasi ini masuk ke dalam wilayah kerja Puskesmas Wonorejo. Data yang didapatkan dari Puskesmas Wonorejo bahwa RT. 3 adalah wilayah yang paling tinggi menyumbang angka kejadian hipertensi yaitu $75 \%$ dari jumlah penduduk. Kejadian hipertensi ini diperparah dengan usia penderita berada pada rentang 30 sampai 60 tahun, termasuk dalam usia produktif.

Survey saat kunjungan didapatkan bahwa warga RT.3 mayoritas adalah warga suku Kutai yang memiliki kebiasaan mengkonsumsi makanan olahan asin seperti jukut pija yang merupakan olahan ikan asin asli dari Kutai, sehingga bisa dipastikan bahwa warga memiliki perilaku yang tidak sehat tentang konsumsi makanan yang berdampak pada meningkatnya tekanan darah. Hipertensi merupakan penyakit degeneratif yang dapat terjadi karena kurangnya pengetahuan seseorang tentang perilaku hidup sehat.

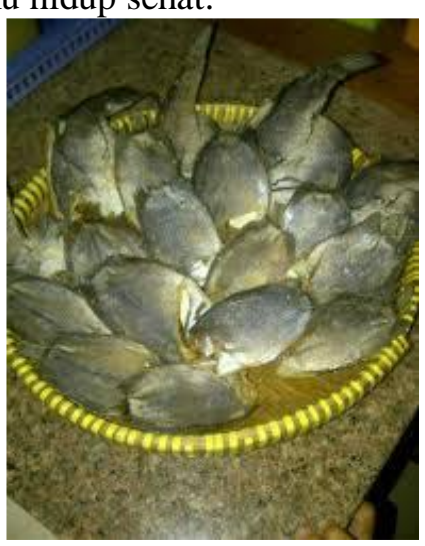

Gambar 1 Olahan Jukut Pija khas suku Kutai yang sering dikonsumsi

\section{METODE}

Kegiatan Pengabdian kepada masyarakat untuk menurunkan tekanan darah penderita hipertensi ini dilakukan kepada penderita hipertensi di wilayah RT.3 Kelurahan Teluk Lerong Ulu. Kegiatan diawali dengan survey lapangan untuk mencari jumlah penderita hipertensi dan diapatkan penderita sebanyak 40 peserta.

Alternatif pemecahan masalah dilakukan dengan mengadakan pendidikan kesehatan seperti bahaya hipertensi, cara pencegahan hipertensi dan pengolahan makanan bagi penderitas hipertensi. Selain itu akan dilakukan simulasi mengenai pengolahan bahan alam yang sudah terbukti dalam penelitian mampu menurunkan tekanan seperti pengolahan teh bawang dayak sehingga masyarakat mampu membuat olahan bahan alam yang mampu menurunkan tekanan darah tinggi. Selain itu diajarkan pula cara mengobservasi tekanan darah tinggi dengan dibuatkan lembar observasi tekanan darah tinggi.

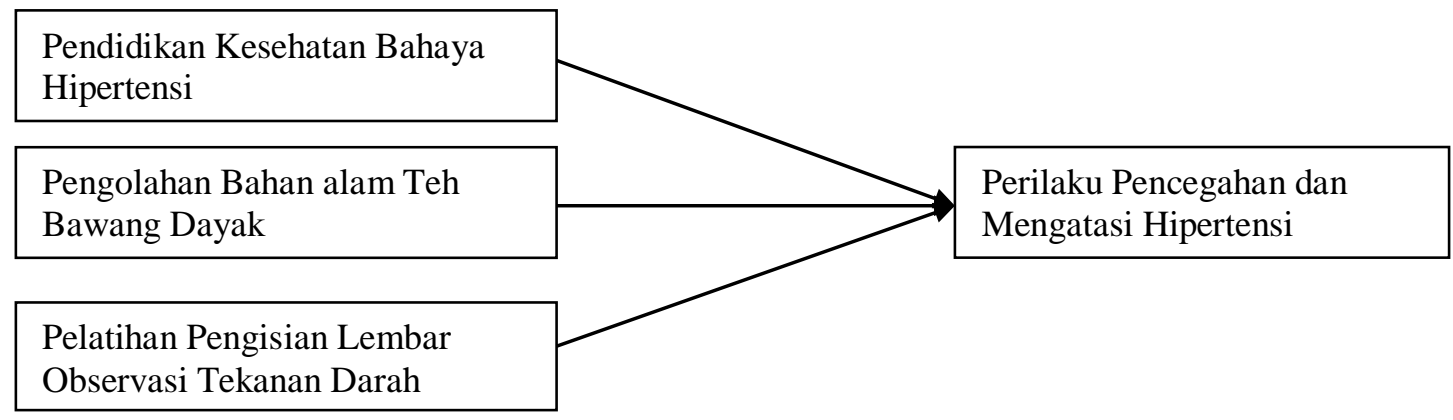


Gambar 2. Strategi Promosi Kesehatan yang digunakan kepada masyarakat

\section{HASIL DAN PEMBAHASAN}

Kegiatan pengabdian masyarakat untuk menurunkan tekanan darah penderita hipertensi dilaksanakan selama 3 hari berturut-turut. Pada hari pertama kegiatan ini diawali dengan menanyakan sejauh mana pengetahuan warga mengenai hipertensi, penyebab hipertensi dan bahaya hipertensi. Mayoritas penderita hipertensi dalam kegiatan ini mengetahuai bahaya hipertensi seperti penyakit jantung, ginjal dan stroke, begitupula pencecgahan hipertensi mayoritas penderita mengetahui seperti tidak makan banyak garam, mengurangi makanan berlemak dan kolesterol.
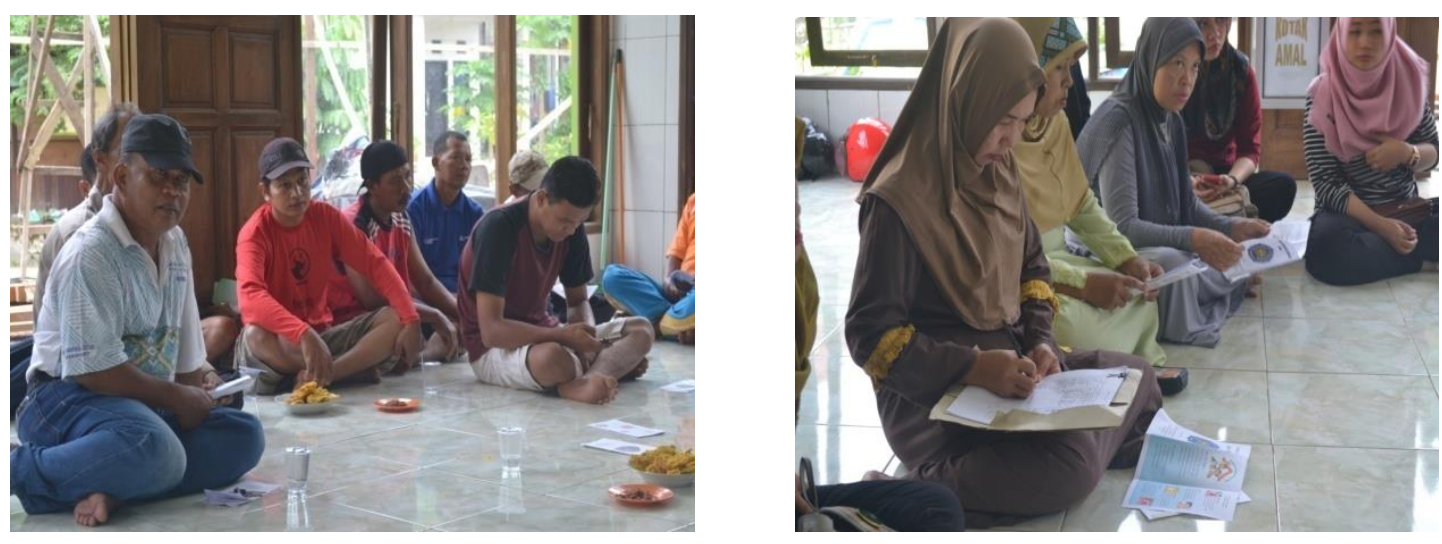

Gambar 3. Pemberian Materi Tentang Bahaya Hipertensi

Penderita hipertensi perlu untuk diberikan pendidikan kesehatan untuk meningkatakan kesadaran tentang bahaya penyakit hipertensi. Dimana dengan memberikan pendidikan kesehatan akan menggugah kesadaran masyarakat tentang penyakit hipertensi yang selama ini mereka derita. Tim pelaksanan pengabdiann kepada masyarakat melibatkan mahasiswa dalam kegiatan ini dengan tujuan agar mahasiswa dapat langsung mempraktekkan pemberian pendidikan kepada masyarakat serta memahami enimena permasalahan yang sering dijumpai oleh masyarakat khusunya tentang penyakit hipertensi.

Pemberian pendidikan kesehatan tersebut ditujukan kepada masyarakat agar mengetahui pecegahan dan pengobatan hipertensi agar tidak memperparah keadaan hipertensinya dan mencegah komplikasi berbahaya dari hipertensi seperti jantung koroner dan stroke. Hal ini sesuai dengan Notoatmodjo (2010), yang mengatakan bahwa pendidikan kesehatan ditujukan untuk menggugah kesadaran, memberikan atau meningkatkan pengetahuan masyarakat tentang pemeliharaan dan peningkatan kesehatan baik bagi dirinya sendiri, keluarganya maupun masyarakatnya. Di samping itu dalam konteks ini pendidikan kesehatan juga memberikan pengertian-pengertian tentang tradisi, kepercayaan masyarakat dan sebagainya, baik yang merugikan maupun yang menguntungkan kesehatan.

Pendidikan kesehatan dalam bentuk penyuluhan ini dilakukan untuk meningkatkan pemahaman penderita hipertensi tentang bahaya penyakit hipertensi. Hipertensi merupakan salah satu penyakit degeneratif yang memiliki tingkat morbiditas dan mortalitas yang tinggi. Tekanan darah tinggi merupakan faktor risiko yang kuat terhadap terjadinya penyakit ginjal dan penyakit-penyakit kardiovaskular seperti stroke dan penyakit jantung iskemik. Individu prehipertensif memiliki kemungkinan tinggi mengalami hipertensi dan peningkatan risiko mengalami penyakit kardiovaskular dibandingkan individu dengan nilai tekanan darah dalam kisaran normal (Rahajeng, 2009). 
Manajemen untuk penderita hipertensi dimulai dengan terapi non-farmakolohik seperti modiikasi gaya hidup (lifestyle) yang sangat erat kaitannya dengan makanan yang

sering dikonsumsi. Warga masyarakat RT. 3 Kelurahan Teluk Lerong memiliki kegemaran untuk mengkonsumsi makanan olahan ikan asin yang disebut jukut pija sehingga dengan pendidikan kesehatan ini terjadi perubahan perilaku untuk mengurangi mengkonsumsi makanan ini.

Pelaksanaan pada hari kedua yaitu mengajarkan membuat olahan bahan alami untuk menurunkan tekanan darah yaitu dengan teh bawang dayak. Umbi bawang dayak (Eleutherine americana Merr) merupakan obat herbal tradisional yang digunakan sebagian masyarakat di daerah Kalimantan dalam bentuk segar. Selain itu, umbi bawang dayak berkhasiat sebagai obat antihipertensi, kencing manis (DM) dan kolesterol. Adapun penggunaan bawang dayak biasanya dipakai \pm 50 gram umbi segar Eleutherine americana, dicuci dengan pelarut kemudian diperas dan disaring. Hasil saringan ditambah $1 / 2$ gelas air matang panas. Diminum sehari 2 kali $1 / 4$ gelas pagi dan sore. Laporan dan penelitian efek negatif dari pemanfaatan bawang dayak belum ditemukan hingga saat ini. Adapun pemanfaatan teh bawang dayak biasanya diolah dengan mengiris umbi bawang dayak dan kemudian mengeringkan di bawah cahaya matahari. Teh bawang dayak yang disarankan untuk penyakit kencing manis yaitu sebanyak 3 sendok teh kemudian direndam dalam gelas berukuran gelas duralex $( \pm 75 \mathrm{~mL})$ dan diminum sebanyak 2 kali sehari sebelum makan karena obat herbal alam lebih mudah diserap sebelum makan (Nirmala, 2010).

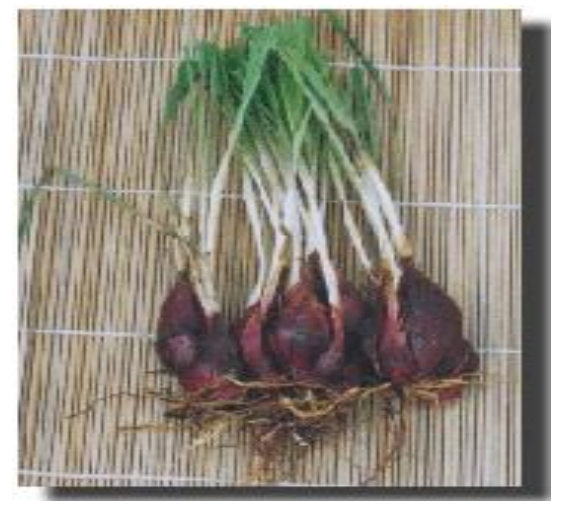

Gambar 4 : Bawang Dayak (Eleutherine americana Merr)

Perlu diajarkan mengenai pengolahan bahan alam kepada masyarakat penderita hipertensi untuk mengurangi penggunaan obat-obatan berbahan kimia yang dapat menimbulkan efek samping (Setyawan, 2016). Senyawa kimia dalam daun alpukat yang telah diketahui berperan aktif dalam mekanisme antihipertensi antara lain flavonoid, saponin dan alkaloid. Flavonoid $\left(\mathrm{C}_{5} \mathrm{H}_{8}\right)$ merupakan salah satu golongan fenol terbesar yang berada di alam. Senyawa tersebut dapat melindungi tubuh dari radikal bebas melalui mekanisme antioksidan. Flavonoid $\left(\mathrm{C}_{5} \mathrm{H}_{8}\right)$ mampu memperbaiki fungsi endotel dan menghambat agregasi platelet. Efek ini merupakan keuntungan flavonoid pada resiko penyakit kardiovaskuler (Febrinda, 2013).

Hari ketiga perlu juga diajarkan mengenai observasi tekanan darah. Harapan dengan mengajarkan penderita hipertensi yaitu agar mengetahui tekanan darah dengan mencatat harian sehingga lebih bisa diamati. Kebanyakan penderita hipertensi setelah melakukan pemeriksaan tekanan darah tidak melakukan pencatatan sehingga setelah beberapa jam kemudian langsung terlupakan. Pelatihan observasi pencatatan tekanan darah ini dilakukan dirumah warga yang tercatat sebagai warta RT.3 yang menderita hipertensi. Hal ini dilakukan agar dapat dilakukan pemeriksaan tekanan darah langsung dengan warga sehingga warga bisa melakukan pencatatan observasi dimulai dari ini.

Melalui observasi tekanan darah ini diharapkan tekanan darah penderita lebih bisa terkontrol dan tidak terkesan masa bodoh dengan kondisi tekanan darahnya. Selain itu 
disampaikan juga kepada warga untuk rutin melakukan pemeriksaan tekanan darahnya minimal 1x seminggu dan kemudina mencatatnya dalam lembar observasi yang telah dibuatkan.
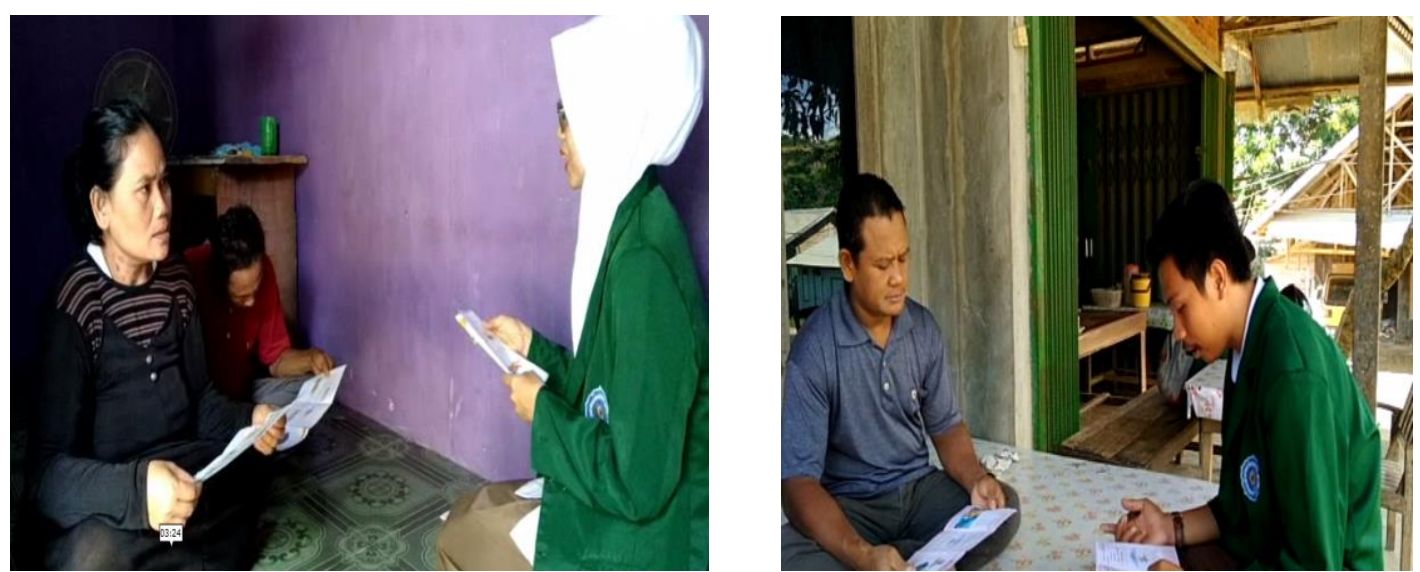

\section{Gambar 4. Pelatihan Pengisian Lembar Observasi Tekanan Darah}

Dengan diberikannya promosi kesehatan melalui pendidikan kesehatan tentang bahaya hipertensi, pengolahan bahan alam untuk menurunkan tekanan darah dan pengisian lembar observasi tekanan darah diharapkan tekanan darah penderita hipertensi di RT. 3 Kelurahan Teluk Lerong Ulu Samarinda dapat menurun. Sebelum dilakukan promosi kegiatan dilakukan pemeriksaan tekanan darah penderita, kemudian dilakukan pemeriksaan tekanan darah satu bulan setelah dilakukan promosi kegiatan sebagai bentuk evaluasi keberhasilan kegiatan pengabdian masyarakat dengan didapatkan hasil analisis sebagai berikut:

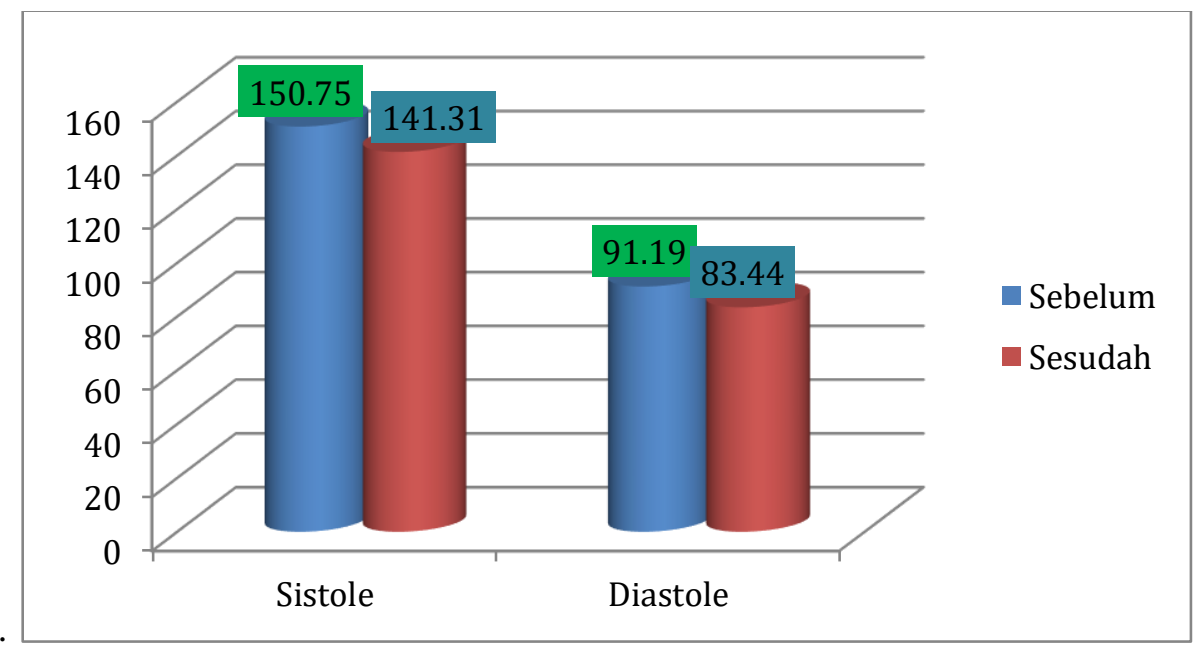

Gambar 5. Perbedaan rata-rata Tekanan Darah Sistole dan Diastole sebelum dan sesudah dilakukan Promosi Kesehatan

Keberhasilan kegiatan pengabdian masyarakat ini ditandai dengan penurunan rata-rata tekanan darah systole dan diastole oleh 40 orang penderita hipertensi di RT. 03 Kelurahan Teluk Lerong Ulu Samarinda. Rata-rata tekanan darah systole sebelum dilakukan promosi kesehatan yaitu $150,75 \mathrm{mmHg}$ menurun menjadi $91,19 \mathrm{mmHG}$ dan rata-rata tekanan darah diastole sebelum dilakukan promosi kesehatan yaitu 141,31 mmHG menurun menjadi 83,44 mmHg. 


\section{KESIMPULAN}

- Promosi kesehatan merupakan metode non farmakologi yang bisa diberikan kepada penderita hipertensi untuk menurunkan tekanan darah.

- Promosi kesehatan dalam kegiatan pengabdian masyarakat ini berupa pendidikan kesehatan tentang bahaya hipertensi, pengolahan bahan alam teh bawang dayak dan pelatihan pengisian lembar observasi tekanan darah.

- Terjadi penurunan rata-rata tekanan darah systole dan diastole penderita hipertensi di RT. 3 Kelurahan Teluk Lerong Ulu Samarinda setelah kegiatan pengabdian kepada masyarakat ini.

\section{SARAN}

Menjaga tekanan darah penderita hipertensi agar tetap stabil dibutuhkan peran serta keluarga sebagai orang terdekat dengan penderita, sebagai bentuk kesinambungan kegiatan seharusnya diadakan pengabdian kepada masyarakat yang berfokus kepada keluarga penderita. Kegiatan tersebut bisa berupa pendidikan kesehatan mengenai peran keluarga dalam hipertensi.

\section{UCAPAN TERIMA KASIH}

Penulis mengucapkan terima kasih kepada LPPM Universitas Muhammadiyah Kalimantan Timur yang telah memfasilitasi pendanaan dengan Surat Perjanjian IuM (IPTEK Untuk Masyarakat) Nomor: 100.7/LPPM/A.4/C/2018 sehingga pengabdian kepada masyarakat ini dapat berjalan. Penulis juga mengucapkan Kepada Ketua Program Studi D-III Keperawatan Universitas Muhammadiyah Kalimantan Timur Ns. Tri Wahyuni, M.Kep, Sp. Mat atas ijin untuk menjalankan kegiatan pengabdian kepada masyarakat ini. Selain itu Penulis mengucapkan terima kasih kepada Ketua RT. 3 Kelurahan Teluk Lerong Ulu Samarinda Bapak Harjanto yang memberikan ijin untuk pelaksanaan kegiatan ini.

\section{DAFTAR PUSTAKA}

[1] Parmawaty. (2012). Hubungan Antara Obesitas Dengan Kejadian Hipertensi. Skripsi, Stikes Muhammadiyah, Program Studi Keperawatan, Samarinda: Tidak diterbitkan

[2] Garnadi, Y. (2012), Hidup Nyaman dengan Hipertensi. Jakarta: Agromedia

[3] Sutaryo. (2011). Bagaimana Menjaga Kesehatan Jantung. Yogyakarta: Cinta Buku

[4] Notoatmodjo, S. (2010). Ilmu perilaku kesehatan . Jakarta: Rineka Cipta.

[5] Rahajeng E, Tum S.(2009). Prevalensi Hipertensi dan Determinannya di Indonesia. Majalah Kedokteran Indonesia.

[6] R. Nirmala. (2010). Budidaya Pengembangan Bawang Tiwai/Bawang Sabrang (Eleutherine americana (L). Merr.). Erlangga. Jakarta

[7] AB Setyawan, ES Lestari, W Winarto . 2016. Ekstrak Daun Kejibeling Meningkatkan Fagositosis Dan Roi Makrofag Pada Mencit Diinfeksi Staphylococcus aureus. Jurnal Kesehatan masyarakat 11 (2) 173-177, 2016

[8] E. Febrinda, A., Astawan, M., Wresdiyati, T., \& Dewi Yuliana, N. (2013). Kapasitas Antioksidan Dan Inhibitor Alfa Glukosidase Ekstrak Umbi Bawang Dayak. Jurnal Teknologi Dan Industri Pangan, 24(2), 161-167. https://doi.org/10.6066/jtip.2013.24.2.161 